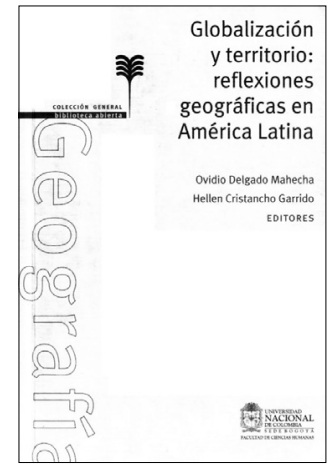

\title{
Ovidio Delgado Mahecha y Hellen Cristancho Garrido (eds.). Globalización y territorio: reflexiones geográficas en América Latina
}

\author{
Bogotá: Universidad Nacional de Colombia, Colección \\ General Biblioteca Abierta, 2009. 412 p.
}

Alex Paulsen E. ${ }^{1}$

Las características propias de la globalización, en su conjunto con el capitalismo, han generado una serie de transformaciones territoriales, las cuales han determinado significativos cambios a nivel latinoamericano, que se han manifestado no tan solo a nivel urbano y rural, sino que también en lo que respecta a la educación y al nacimiento de nuevos nichos epistemológicos de la geografía, como las llamadas geografías del miedo y de la televisión. De esta guisa, la antología que se pasa a reseñar, "tiene la intencionalidad de poner en discusión diferentes puntos de vista de la geografía latinoamericana, que tocan aspectos relacionados con los desarrollos teóricos y metodológicos del discurso geográfico contemporáneo; el cambio urbano; la transformación de los espacios rurales; los problemas ambientales y la educación geográfica" (Delgado y Cristancho, 2009: 16). Los diferentes escritos que componen este libro fueron presentados en el XI Encuentro de Geógrafos de América Latina (XI EGAL), realizado en Bogotá en marzo de 2007.

En la primera parte, llamada Discursos de la geografía latinoamericana, nos encontramos con un análisis teórico que tiene como hilo conductor a los procesos referidos a la globalización y el capitalismo y su impacto en el territorio, además de reformular paradigmas que hacen alusión a la geografía

\footnotetext{
1 Magíster (C) en Geografía y Geomática. Instituto de Geografía, Pontificia Universidad Católica de Chile (Chile). E-mail: appaulse@uc.cl
}

cuantitativa a partir de la introducción de aplicaciones automatizadas a través de Sistemas de Información Geográfica (SIG), así como también planteamientos teóricos que surgen fundamentalmente a raíz de una discusión sobre la geografía histórica. Es interesante destacar que existe una intención (así como también una percepción) por parte de los autores de una falta de reflexión que aumente el corpus teórico de la geografía. En tal sentido el "problema ha sido la extrema especialización dentro de la propia geografía, que ha conducido a ignorar la necesidad de fortalecer un núcleo epistemológico" (Delgado y Cristancho, 2009: 32). Asimismo, el impacto que ha generado la globalización en las líneas de investigación de la geografía, se puede evidenciar en la falta de producción de conocimiento teórico, por lo que "una de las cosas más importantes que debíamos hacer los geógrafos interesados en estos tópicos, era preocuparnos por el método, ya que de esta forma estaríamos transitando el camino que nos conduciría a la teoría, de la que tan carente esta nuestra ciencia, mucho más en estos tiempos de globalización" (Delgado y Cristancho, 2009: 57).

Además de la existencia de un discurso teórico importante en las primeras páginas del texto, también es menester destacar los análisis realizados sobre la globalización, ya que nos permiten entender la lógica espacial capitalista que ha operado en Latinoamérica y, sobre todo en lo referido a los circuitos inferiores de la economía, donde la racionalidad y la irracionalidad (propios de esta época histórica en la que nos encontramos) provocan 
situaciones como la exclusión socioterritorial, las desigualdades sociales a partir de la dualidad Estado-mercado y la división territorial del trabajo. En consecuencia "las áreas menos tecnificadas, capaces de permitir acciones más libres, o las acciones que no están basadas en técnicas de acción, aparecen como manifestaciones de irracionalidad. Las grandes metrópolis latinoamericanas, sede de la más aguda racionalidad del periodo y por eso de la producción ampliada de escasez, aparecen también como abrigo de manifestaciones «irracionales», entre ellas el circuito inferior de la economía urbana" (Delgado y Cristancho, 2009: 34). Por su parte la desterritorialización también ha jugado un papel importante, en el entendido que el territorio ha perdido su papel de obstáculo y generador de costos de fricción, a favor de un capital que se mueve sin importar las fronteras de los Estados-nacionales, ni tampoco de sus leyes.

En la segunda parte de esta antología, apreciamos las diferentes manifestaciones territoriales que ha generado la globalización, en varias ciudades latinoamericanas. Luego, el concepto que guía la discusión en este apartado estará representado por la llamada lógica espacial capitalista (parafraseando a Méndez), ya que como menciona Ciccolella, la emergencia de nuevas territorialidades durante la década de los noventa, estará caracterizada por la expansión de las áreas metropolitanas y la conformación de una morfología de archipiélago urbano, aduciendo que "la formación de este tipo de espacio parece ser la transposición o forma material de una condición emergente del capitalismo global-neoliberal: la fluidez" 2 (Delgado y Cristancho, 2009: 105). Asimismo, la existencia de procesos como la gentrificación, la suburbanización de tipo «americanizante» y la dualización. Bajo esta perspectiva, los nuevos artefactos urbanos también serán propios

\footnotetext{
2 Estos procesos son consecuencia de la creciente liberalización económica apoyada por el Estado, lo cual ha decantado en que este último haya perdido control sobre "el proceso de transformación territorial urbana. El problema parece oscilar entre la existencia de vacíos normativos, de normativa obsoleta, de existencia de normas pero no de voluntad política de aplicarlas o de ajustar las tendencias del mercado a las normas preexistentes" (Delgado y Cristancho, 2009: 112).
}

de una globalización que homogeneizará los estilos de vida; tales son los ejemplos de "malls, shopping centers, super e hipermercados diversificados y especializados, centros financieros, centros empresariales, zonas hoteleras, distritos industriales y tecnológicos" (...) así como también, "la fragmentación del espacio urbano: coexistencia conflictiva de múltiples ciudades, la de los incluidos y la de los excluidos" (...), la "privatización del espacio público, calles, zonas residenciales y espacios de ocio" (Delgado y Cristancho, 2009: 128), entre otros. Ahora bien, no tan solo los cambios a nivel territorial han sido patentes en la ciudad, sino que también lo relativo al mercado del trabajo y su pauperización, en cuanto a depreciación de las remuneraciones de los trabajadores. Fundamentalmente, "as transformações ocorridas na dinámica do emprego industrial se fizeram acompanhar pela diminuição da quantidade de horas pagas na industria, a pesar do crecimiento de sua produção física, ou seja, a pesar do crescimento no numero de productos produzidos. Dizendo de uma outra maneira, se produz mais, sim, mas se paga, cada vez, menos" (Delgado y Cristancho, 2009: 153). A partir de estas constataciones (urbanas y laborales), se ha instalado una sensación que permitiría hablar de la geografía del miedo, ya que ante la irrupción de la globalización y el capitalismo, los modos de vida metropolitanos se territorializan con las Ilamadas gatted community. El individuo busca no tan solo seguridad en este tipo de urbanización, sino que también una forma de evitar la alteridad y con ello cualquier tipo de contacto con aquello que le es extraño, lo que en definitiva da muestras de un individualismo exacerbado, por ejemplo, la discriminación hacia los individuos que viven de manera diferente en el fraccionamiento (por desplazarse en bicicleta o por tener una religión distinta que la católica) recalca aún más crudamente el conformismo social y el miedo a los demás, que es hasta el interior y no hasta el exterior que se manifiesta" (Delgado y Cristancho, 2009: 169). Las lógicas que se concretan en el territorio muestran aspectos profundos de una sociedad que construye su espacio a partir de sus percepciones urbanas en conjunto con esta (ir)racionalidad económica.

El tercer apartado está dedicado a las transformaciones de los espacios rurales, a 
partir de la nueva configuración socioterritorial de la ciudad, en virtud de la expansión urbana de los sectores medios, medios-altos y altos, proceso que se ha denominado periurbanizacón. En concomitancia con este proceso, el desarrollo inmobiliario de las viviendas de interés social, también ha contribuido a la expansión de la ciudad de Santiago con apoyo del Estado, principal ente promotor de este tipo de edificaciones, y por lo tanto quien delimita esta precariópolis estatal, según Hidalgo. A esto se suma que las intervenciones en el ámbito rural, también han provocado problemas identitarios, ya que a partir de la reforma agraria en Brasil, los campesinos en su nueva relocalización, han perdido parte de su cultura en virtud de la desterritorialización que han sufrido. A partir de esta relocalización, "a construçao de um novo espaço tras consigo a história de vida de cada um não só dentro do contexto histórico, mas também a partir do seu imaginário social. A reconstrução de sua identidade com o novo territorio será marcada por suas refêrencias anteriores complementadas pela troca de conhecimientos e de vivencias cotidianas (...)" (Delgado y Cristancho, 2009: 207). Esta situación que sufre el campesinado de Brasil también está ligada a su inserción en el contexto mundial del comercio, ya que según Segrelles, autor del texto "América Latina y la Unión Europea: competencia comercial de la agricultura", los mecanismos de la Unión Europea se basan en un proteccionismo no arancelario, que está sujeto a cláusulas netamente ecológicas, "a la multifuncionalidad rural o a la calidad alimentaria como nuevas trabas" (Delgado y Cristancho, 2009: 224) para los mercados latinoamericanos. Es decir, los aspectos relativos a lo rural están siendo afectados por la globalización y el capitalismo, en sus dinámicas territoriales, humanas y comerciales, debido a un Estado que incentiva la formación de periferias pobres, relocalización del campesinado y su desarraigo, así como también la mantención de esta dualidad centro-periferia, por parte de la Unión Europea.

La cuarta parte está compuesta por dos artículos que hacen alusión a los retos para la sostenibilidad ambiental. El contexto histórico en el cual nos encontramos actualmente ha determinado estilos de vida y procesos productivos propios de un capitalismo que en primera instancia crea nuevas necesidades (es decir, estilos de consumo) y por lo tanto nuevos modos de producción. En consecuencia, se ha establecido un paradigma en el cual las lógicas de la naturaleza, están siendo sobrevaloradas y por tanto, su regeneración ha sido obviada por parte del sistema económico. En función de lo anteriormente dicho es que las medidas económicas que se han implantado Latinoamérica, han seguido el camino de las comodificaciones, es decir, la privatización de los recursos naturales. Por ende, "el acceso a los bienes y servicios territoriales y ambientales, que con anterioridad formaban parte de los espacios comunes, dependen cada vez más del poder adquisitivo de los habitantes de campos y ciudades (...) generando así toda una narrativa que asegura que solo la privatización garantiza los niveles de eficiencia en su disponibilidad libre" (Delgado y Cristancho, 2009: 253). Esto convertirá a la inequidad en una patología crónica de los países latinoamericanos. Teniendo en cuenta esta incesante actividad industrial que es parte de la racionalidad neoliberal, el cambio climático se presenta ante nosotros, como una crisis de modelos ya sea de consumo, económicos, políticos y culturales, debido a sus injerencias sobre el medio. La alta montaña sufre de estas consecuencias y en el artículo de Flores, "La alta montaña y el cambio climático", se presentan resultados que apuntan a afirmar que "el cambio climático expresado en el incremento térmico, es mayor en la alta montaña en relación con otros espacios" (Delgado y Cristancho, 2009: 310) explicando el derretimiento de los glaciares, pero también, "el ascenso de la frontera agrícola y, de aquí, los impactos ambientales en los suelos, regulación del régimen hídrico, aumento de la efectividad de la disección y del escurrimiento y sedimentación del sistema lagunar con la consecuente disminución de las reservas hídricas y su regulación" (Delgado y Cristancho, 2009: 312). Existe un reto para la sostenibilidad, a saber: mejorar los mecanismos (dígase jurídicos y culturales) que ayuden a corregir esta lógica territorial capitalista en su dimensión económica y ecológica, es decir, tratar de que los ciclos económicos se ajusten a los ciclos naturales.

Finalmente, la última parte de esta interesante antología de textos, está abocada a destacar algunos aspectos de la educación 
geográfica a nivel escolar y superior, así como también características que permiten señalar a la geografía como una ciencia que posibilita desarrollar habilidades y conocimientos en los individuos. Esta enseñanza de la geografía se inserta en un contexto en el cual la problemática ambiental es algo contingente, por lo que la geografía adquiere un rol preponderante no tan solo como ciencia que posee una epistemología y metodología afín, al momento de establecer teorías que nos permitan explicar esta problemática, sino que también adquiere un rol pedagógico al permitir desarrollar un pensamiento espacial y la comprensión de las relaciones que existen entre el individuo y el medio. Esto está coadyuvado por la didáctica de la geografía, la cual es "la disciplina de la enseñanza y del aprendizaje planificado, con tareas, contenidos y problemas de geografía" (Delgado y Cristancho, 2009: 342), además de herramientas cognitivas que nos permiten saber qué tipo de conocimiento es el correspondiente a cada nivel propio del desarrollo cognitivo del ser humano. Ahora bien, los textos nos invitan a reflexionar en torno a la formación inicial de los profesores de geografía en donde la nueva realidad incita a reflexionar y adaptar los nuevos conocimientos propios de la ciencia, a la realidad escolar, sobre todo en lo que es la aplicación de nuevas tecnologías en el proceso de enseñanza-aprendizaje, siendo la televisión (sobre todo en esta sociedad que es netamente visual), un elemento didáctico muy potente al momento de desarrollar este pensamiento espacial. Esto nos lleva a pensar en la realidad actual de Chile, ya que la enseñanza de la geografía se reduce a una concepción que no reflexiona sobre las relaciones entre ser humano y el medio, sino que está determinada por una acumulación memorística de lugares, climas y países. Esto se ha de apreciar en la presencia (o mejor dicho ausencia) de la geografía en los planes y programas que establece el Ministerio de Educación, en donde esta ciencia solo se limita a recursos naturales, regiones de Chile y sus climas, además de proponer los riesgos naturales y antrópicos, así como también la transformación del paisaje del medio por acción del hombre. Esta concepción de la geografía ha estado alimentada por una formación inicial docente en donde la geografía no ha sido mayormente desarrollada, por lo cual al momento de aplicar las unidades que corresponden al desarrollo de la espacialidad en los estudiantes, los docentes en muchos casos solo dan una pincelada al tema e incluso no lo llegan a tratar en clases.

\section{Consideraciones finales}

La estructura del libro que ha pasado a ser reseñado, nos permite señalar que posee la virtud de realizar una reflexión no tan solo a nivel de investigación empírica, sino que también existe un desarrollo teórico muy importante, ya que la reflexión teórica sobre geografía es una práctica no muy desarrollada, de hecho, esto es señalado durante el texto. Por lo tanto es un aporte considerable para generar un corpus que alimente la episteme de la geografía. Por otro lado es totalmente destacable que se aborde el tema de la educación en una antología de textos de una disciplina como la geografía, ya que el desarrollo de una concepción menos reduccionista solo puede ser posible a través de un proceso tan importante como lo es la educación. Esto se hace aun más relevante en un contexto en el cual la globalización está realizando complejos cambios a nivel territorial, social, cultural, político, económico y ambiental, por lo que se hace necesaria la reflexión y educación de quienes nos encontramos en un contexto histórico en particular como es este. Asimismo, es menester señalar que la presencia del pensamiento de Milton Santos se hace patente en la cantidad de aportes bibliográficos que son de su autoría y que son utilizados por los diferentes autores. Esto último nos remite a la necesidad que existe de reflexionar desde América Latina, para que de esta forma se vaya desarrollando un pensamiento propio, una tradición latinoamericana, que nos caracterice desde la geografía y por lo tanto es esencial realizar textos como el que acabamos de reseñar. Fundamentalmente, se hace necesaria esta reflexión y este pensamiento latinoamericano, para que así nuestra construcción del espacio se haga desde nosotros y no a partir de un conocimiento marcadamente eurocentrista, ya que si miramos históricamente, América Latina siempre ha sido un lugar en donde la colonización de lo imaginario se ha hecho desde el centro y no desde la periferia, no desde nosotros. 